\title{
An Unusual Case of Obstructive Jaundice Secondary to Pyogenic Liver Abscesses
}

\author{
Shannon K. Brewer ${ }^{1}$, Pranav Patel ${ }^{2}$, Riad Kesiry ${ }^{2}$ \\ 1. Internal Medicine, University of North Texas Health Science Center, Fort Worth, USA 2. Internal Medicine, Medical \\ City Weatherford, Weatherford, USA
}

Corresponding author: Shannon K. Brewer, shannonkbrewer@outlook.com

\begin{abstract}
Pyogenic liver abscesses (PLA) are an uncommon, but potentially life-threatening infection. Although the link between amebic liver abscesses and obstructive jaundice is well documented, there are few cases of PLA leading to this complication. We present a case of multiple massive PLA and obstructive jaundice on initial presentation. The patient was treated for six weeks with antibiotics and percutaneous drains placed in the largest abscesses and was discharged after clinical improvement and resolution of the hyperbilirubinemia. This case highlights the importance of clinician awareness of other etiologies when evaluating patients with signs and symptoms of painful obstructive jaundice.
\end{abstract}

Categories: Internal Medicine, Gastroenterology

Keywords: pyogenic abscess, liver abscess, obstructive jaundice, cholestasis, liver abscess aspiration

\section{Introduction}

The formation of hepatic abscesses secondary to bacteria has been well established; however, extensive disease-causing obstructive jaundice is rare. Pyogenic liver abscesses (PLA) are uncommon, but account for approximately $80 \%$ of all hepatic abscesses [1] and are associated with significant rates of mortality. The most common causative organisms of PLA include Streptococcus anginosus group organisms anaerobes, and gram-negative bacteria including Escherichia coli and Klebsiella pneumoniae [2]. Obstructive jaundice is a rare manifestation of PLA. Here we present a case of multiple massive PLA presenting as obstructive jaundice in an immunocompetent patient.

\section{Case Presentation}

A 48-year-old Hispanic male with no significant past medical history presented with four days of right upper quadrant abdominal pain and vomiting. Upon presentation, he was febrile and tachycardic. Physical examination was notable for right upper quadrant abdominal tenderness, hepatomegaly, and jaundice. He denied any recent travel, alcohol use, or illicit drug use.

Review began 06/25/2021 Review ended 07/06/2021 Published 07/15/2021

\section{๑) Copyright 2021}

Brewer et al. This is an open access article distributed under the terms of the Creative Commons Attribution License CC-BY 4.0., which permits unrestricted use, distribution, and reproduction in any medium, provided the original author and source are credited.
Labs were significant for leukocytosis of $27.67 \times 10^{3} / \mu \mathrm{L}$ with neutrophilic predominance and lactic acid 2.9 $\mathrm{mmol} / \mathrm{L}$. The results of hepatic-function tests suggested obstructive jaundice with total bilirubin $14.0 \mathrm{mg} / \mathrm{dL}$, direct bilirubin $11.35 \mathrm{mg} / \mathrm{dL}$, aspartate aminotransferase $388 \mathrm{U} / \mathrm{L}$, alanine aminotransferase $271 \mathrm{U} / \mathrm{L}$, and alkaline phosphatase $480 \mu / \mathrm{L}$. Blood cultures revealed $S$. constellatus bacteremia. Transthoracic echocardiogram was unremarkable. Extensive evaluation for underlying malignancy or other predisposing infectious etiologies, including carcinoembryonic antigen, cancer antigen 19-9, serum alphafetoprotein tumor markers, hepatitis, and HIV serologies, was negative.

Abdominal ultrasound showed multiple hepatic masses. Computed tomography (CT) of the abdomen revealed marked hepatomegaly and innumerable low-density masses throughout the liver with a large complex mass in the right lobe measuring up to $12 \mathrm{~cm} \times 16 \mathrm{~cm}$ (Figure 1), redemonstrated by triple-phase magnetic resonance imaging (MRI) of the abdomen (Figure 2). Cultures from liver abscess aspiration revealed $S$. intermedius. 


\section{Cureus}

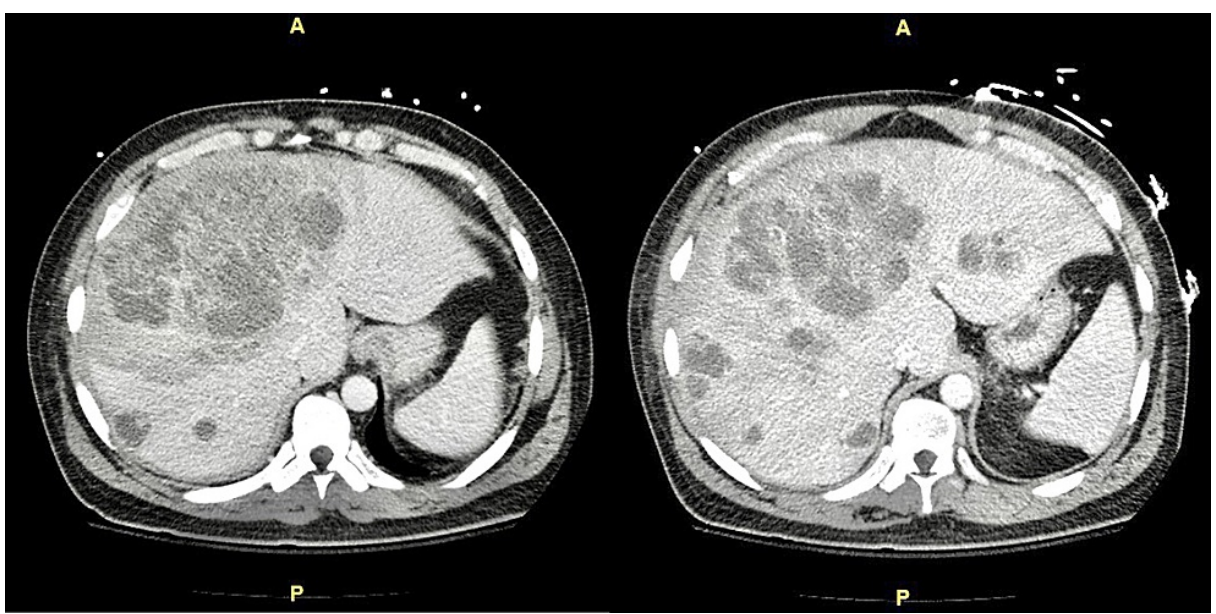

FIGURE 1: Computed tomography of the abdomen showing innumerable low-density hepatic lesions throughout with the largest complex lesion centered about the right lobe measuring $12 \mathrm{~cm} \times 16 \mathrm{~cm}$.

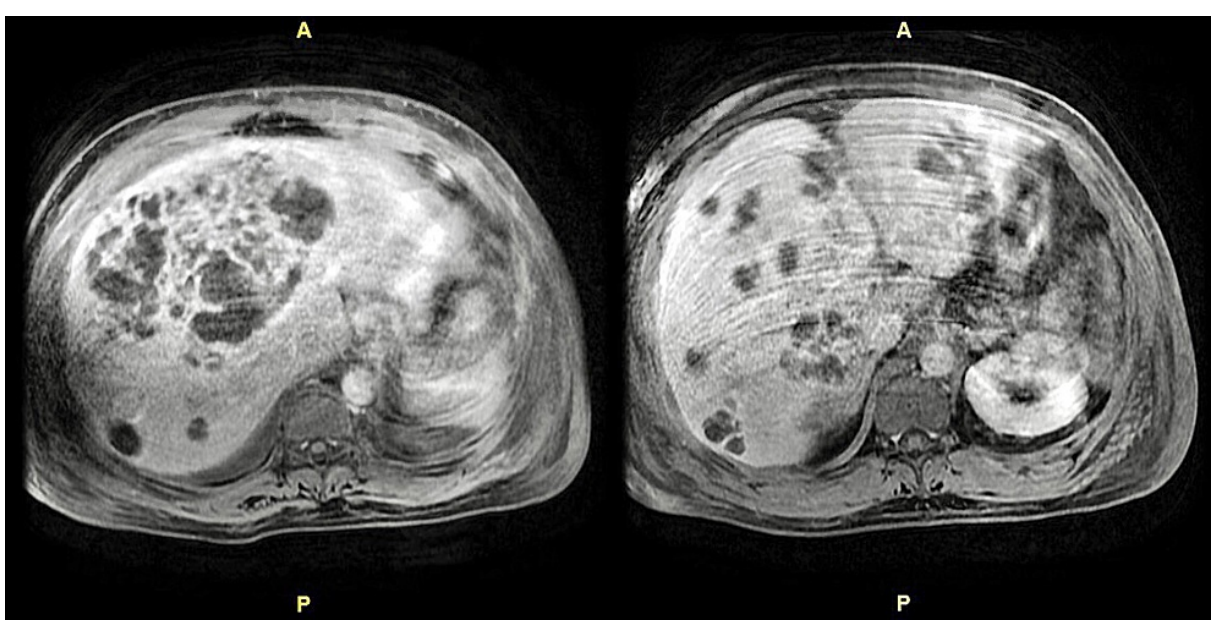

FIGURE 2: Triple-phase magnetic resonance imaging of the abdomen redemonstrating innumerable hepatic abscesses with the largest lesion demonstrating phlegmon-like features.

The patient was treated with broad-spectrum antibiotics and two percutaneous drains were placed in the largest abscesses, producing a significant amount of drainage with considerable clinical improvement and subsequent removal of the drains after four weeks. He was discharged and completed six weeks of daptomycin without further incidence.

\section{Discussion}

PLA are rare, occurring in 2.3 cases per 100,000 hospital admissions [3], but account for the majority of hepatic abscesses. The most common causative organisms isolated in PLA cultures were E. coli (32\%) and $K$. pneumoniae (45\%) [4]. Other common organisms include S. aureus (20\%), Streptococcus species (3.4-15.5\%), and polymicrobial infections (7.6-79\%) [5,6]. Sources of PLA include cryptogenic (56\%), biliary (15.5\%), intraabdominal sources via the portal vein (15\%), hematogenous (13.5\%) [4,7], direct extension from localized disease, and trauma [8]. Patients with immune deficiency, malignancy, sickle cell anemia, diabetes mellitus, and liver transplant have a high risk of developing a liver abscess [9]. Mortality associated with PLA is approximately $30 \%$ despite appropriate treatment and can be as high as $80-100 \%$ if left untreated [7]. Concurrent malignancy, abscess multilocation, hemoglobin less than $10 \mathrm{~g} / \mathrm{dL}$, total bilirubin greater than $1.05 \mathrm{mg} / \mathrm{dL}$, and failure of percutaneous drainage are risk factors associated with higher mortality rates. Notably, mortality is higher in patients with multiple liver abscesses compared to those with a solitary lesion $[7,10]$. 
Multiple abscesses account for approximately $33 \%$ of cases [9], are of biliary origin (45\%), and often associated with $E$. coli, whereas single abscesses are typically cryptogenic (58.9\%) and often associated with K. pneumoniae [10]. Mortality rates in patients with multiple liver abscesses and single liver abscesses are $22.1 \%$ and $12.8 \%$, respectively $[7,10]$.

Traditionally, PLA were treated with surgical drainage and broad-spectrum antibiotics. However, with the advent of minimally invasive procedures, the gold standard has shifted to ultrasound or CT-guided percutaneous intervention alongside culture-guided antibiotic therapy $[4,8]$. However, primary surgical intervention is still recommended in cases with abscess rupture, multiloculated abscesses, biliary communication, or inadequate percutaneous drainage [8].

Hepatic abscesses have a classic triad of clinical syndromes that include right upper quadrant pain, fever, and jaundice that is only seen in $10 \%$ of patients [7]. Hyperbilirubinemia is a relatively uncommon presentation in PLA with elevated total serum bilirubin levels noted in $12.5-36.2 \%$ of cases [4,11].

The pathophysiology of obstructive jaundice secondary to PLA is likely due to compression and distortion of the biliary tree by the abscesses, causing intrahepatic cholestasis. Multiple and single large amoebic liver abscesses on the inferior surface near the porta hepatitis were seen most often in cases of hepatic duct compression in patients with jaundice [12-14]. Similar pathophysiology was seen in several cases of patients with polycystic liver disease $[15,16]$.

Benign causes of obstructive jaundice include choledocholithiasis (62.5\%), biliary strictures (25\%), and chronic pancreatitis (6.3\%) [17]. Malignant causes include carcinoma of the gallbladder (28.7\%), carcinoma of the pancreas (26.5\%), and cholangio-carcinoma (10.8\%) [18]. Obstructive jaundice secondary to PLAs is exceedingly rare with few documented cases in the literature $[19,20]$. However, other cases of obstructive jaundice secondary to amebic liver abscesses have been well established [12,14]. Cholestasis with hyperbilirubinemia is present in $29 \%$ of amebic liver abscess cases and levels of serum bilirubin are directly correlated to the size and number of abscesses [12]. Although mild jaundice is a common finding in patients with amebic liver abscess, severe obstructive jaundice is a rare complication [18]. In cases of amebic liver abscesses, jaundice is observed in 8-22\% of patients [13]. Additionally, patients with obstructive jaundice have increased mortality when compared with non-jaundiced patients undergoing surgical procedures, thus emphasizing the importance of early detection [17].

\section{Conclusions}

This case illustrates a unique presentation of obstructive jaundice secondary to pyogenic hepatic abscesses. This complication of PLA is rare and, to our knowledge, there are only two other similar cases in the literature. This case highlights the importance of clinician awareness of other etiologies when evaluating patients with signs and symptoms of painful obstructive jaundice.

\section{Additional Information}

\section{Disclosures}

Human subjects: Consent was obtained or waived by all participants in this study. Conflicts of interest: In compliance with the ICMJE uniform disclosure form, all authors declare the following: Payment/services info: All authors have declared that no financial support was received from any organization for the submitted work. Financial relationships: All authors have declared that they have no financial relationships at present or within the previous three years with any organizations that might have an interest in the submitted work. Other relationships: All authors have declared that there are no other relationships or activities that could appear to have influenced the submitted work.

\section{References}

1. Heneghan HM, Healy NA, Martin ST, Ryan RS, Nolan N, Traynor O, Waldron R: Modern management of pyogenic hepatic abscess: a case series and review of the literature. BMC Res Notes. 2011, 4:80. 10.1186/1756-0500-4-80

2. Tran MP, Caldwell-McMillan M, Khalife W, Young VB: Streptococcus intermedius causing infective endocarditis and abscesses: a report of three cases and review of the literature. BMC Infect Dis. 2008, 8:154. 10.1186/1471-2334-8-154

3. McKaigney C: Hepatic abscess: case report and review. West J Emerg Med. 2013, 14:154-7. 10.5811/westjem.2012.10.13268

4. Mangukiya DO, Darshan JR, Kanani VK, Gupta ST: A prospective series case study of pyogenic liver abscess: recent trands in etiology and management. Indian J Surg. 2012, 74:385-90. 10.1007/s12262-011-0397-0

5. Brook I, Frazier EH: Microbiology of liver and spleen abscesses. J Med Microbiol. 1998, 47:1075-80. 10.1099/00222615-47-12-1075

6. Yang CC, Yen $\mathrm{CH}$, Ho MW, Wang JH: Comparison of pyogenic liver abscess caused by non-Klebsiella pneumoniae and Klebsiella pneumoniae. J Microbiol Immunol Infect. 2004, 37:176-84.

7. Balint TD, Bailey BM, Mendelson KG, Pofahl W: Hepatic abscess: current concepts in diagnosis and treatment. Curr Surg. 2001, 58:381-4. 10.1016/s0149-7944(01)00456-1

8. Barakate MS, Stephen MS, Waugh RC, Gallagher PJ, Solomon MJ, Storey DW, Sheldon DM: Pyogenic liver 
abscess: a review of 10 years' experience in management. Aust N Z J Surg. 1999, 69:205-9. 10.1046/j.14401622.1999.01523.x

9. Rahimian J, Wilson T, Oram V, Holzman RS: Pyogenic liver abscess: recent trends in etiology and mortality . Clin Infect Dis. 2004, 39:1654-9. 10.1086/425616

10. Chou FF, Sheen-Chen SM, Chen YS, Chen MC: Single and multiple pyogenic liver abscesses: clinical course, etiology, and results of treatment. World J Surg. 1997, 21:384-8; discussion 388-9. 10.1007/pl00012258

11. Zhu X, Wang S, Jacob R, Fan Z, Zhang F, Ji G: A 10-year retrospective analysis of clinical profiles, laboratory characteristics and management of pyogenic liver abscesses in a chinese hospital. Gut Liver. 2011, 5:221-7. 10.5009/gnl.2011.5.2.221

12. Nigam P, Gupta AK, Kapoor KK, Sharan GR, Goyal BM, Joshi LD: Cholestasis in amoebic liver abscess. Gut. 1985, 26:140-5. 10.1136/gut.26.2.140

13. Chan WW, Showler A, Boggild AK: Parasitic liver disease in travelers . Infect Dis Clin North Am. 2012, 26:755-80. 10.1016/j.idc.2012.05.006

14. Sarda AK, Mittal R: An unusual case of amoebic liver abscess presenting with hepatic encephalopathy: a case report. Malays J Med Sci. 2011, 18:79-81.

15. Dmitrewski J, Olliff S, Buckels JA: Obstructive jaundice associated with polycystic liver disease . HPB Surg. 1996, 10:117-20. 10.1155/1996/83547

16. Mehtsun WT, Patel MS, Markmann JF, Hertl M: Obstructive jaundice caused by a giant non-parasitic hepatic cyst. Ann Hepatol. 2015, 14:267-9. 10.1016/s1665-2681(19)30790-2

17. Chalya PL, Kanumba ES, McHembe M: Etiological spectrum and treatment outcome of obstructive jaundice at a University Teaching Hospital in northwestern Tanzania: a diagnostic and therapeutic challenges. BMC Res Notes. 2011, 4:147. 10.1186/1756-0500-4-147

18. Sharma MP, Ahuja V: Aetiological spectrum of obstructive jaundice and diagnostic ability of ultrasonography: a clinician's perspective. Trop Gastroenterol. 1999, 20:167-9.

19. Dohmen K, Shimada T, Onohara S, Shirahama M, Miyamoto Y, Irie K, Ishibashi H: Obstructive jaundice due to multiple hepatic abscesses. Fukuoka Igaku Zasshi. 1998, 89:277-81.

20. Kwon H: Hepatic abscess with biliary obstruction mimicking cholangiocarcinoma-a case report . J Gastrointest Cancer. 2019, 50:328-30. 10.1007/s12029-017-0012-0 